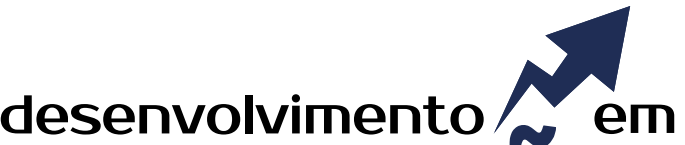 QUESTÂO
}

\section{Negócios Sociais em Foco \\ O caso da Yunus Social Business}

http://dx.doi.org/10.21527/2237-6453.2019.47.102-119

Recebido em: 25/4/2017

Aceito em: 26/12/2018

\section{Lilian de Lima Pires ${ }^{1}$, Luís Miguel Luzio dos Santos², Nicole Cerci Mostagi}

\begin{abstract}
RESUMO
Em um contexto global marcado pela instabilidade e pela crise, questiona-se a abordagem exclusivamente economicista das organizações, uma vez que as empresas motivadas exclusivamente pelo lucro acabam contribuindo para o agravamento da concentração de poder e riqueza e para o aprofundamento das desigualdades, pobreza e degradação ambiental. Ao considerar a relevância do papel das organizações na sociedade contemporânea, emerge a importância de compreender modelos organizacionais capazes de contribuir para a mitigação dos problemas sociais vigentes. $O$ foco deste artigo são empreendimentos que têm como principal propósito resolver um problema social utilizando métodos de negócios. Desse modo, este artigo tem como objetivo descrever a aceleradora de negócios sociais Yunus Social Business (YSB) e sua forma de atuação no contexto mundial. Optou-se por uma abordagem qualitativa de caráter exploratório e descritivo com a utilização de análise documental. São descritas as formas de atuação desses empreendimentos, regiões de atuação e alguns resultados alcançados. A relevância da YSB é reconhecida, no entanto problematiza-se se a atuação dos negócios sociais segue uma lógica paliativa, contribuindo localmente para a mitigação dos problemas sociais sem alterar as mesmas estruturas causadoras de tamanhas crises.
\end{abstract}

Palavras-chave: Negócio social. Yunus Social Business. Crise. Desigualdades.

\section{SOCIAL BUSINESS IN FOCUS: THE YUNUS SOCIAL BUSINESS CASE}

\begin{abstract}
In a global context marked by instability and crisis, the exclusively economicist approach of organizations is questioned, since profit-driven companies end up contributing to the aggravation of concentration of power and wealth and to the deepening of inequalities, poverty and Ambiental degradation. When considering the relevance of the role of organizations in contemporary society, the importance of understanding organizational models capable of contributing to the mitigation of current social problems emerges. The focus of this article are ventures whose main purpose is to solve a social problem using business methods. Thus, this article aims to describe the social business accelerator Yunus Social Business (YSB) and its way of acting in the global context. We chose a qualitative exploratory and descriptive approach with the use of documentary analysis. The ways in which these ventures are described, their areas of action and some results achieved are described. The relevance of the YSB is recognized, however, it is problematic if the social business operations follow a palliative logic, contributing locally to the mitigation of social problems without changing the same structures causing such crises.
\end{abstract}

Keywords: Social business. Yunus Social Business. Crisis. Inequalities.

\footnotetext{
${ }^{1}$ Mestre em Administração pela Universidade Estadual de Londrina (UEL). lilianpires@outlook.com

${ }^{2}$ Doutor em Ciências Sociais pela Pontifícia Universidade Católica de São Paulo (PUC-SP). Professor da Universidade Estadual de Londrina (UEL).Imig@uol.com.br

${ }^{3}$ Mestre em Administração pela Universidade Estadual de Londrina (UEL). Professora da Universidade do Norte do Paraná (Unopar). nicole_cerci@hotmail.com
} 
O período histórico atual é marcado pela convergência de crises. Não se trata apenas de uma crise financeira, mas de multicrises, de modo que os elementos constituintes são reforçados mutuamente. As crises econômica e financeira evidenciaram as falhas e limitações do atual sistema econômico capitalista, com o agravamento das desigualdades sociais e o crescente distanciamento entre ricos e pobres (POCHMANN, 2015). Isso ficou evidente em 2008, quando o caráter global da crise financeira impulsionou um novo debate sobre as rápidas transformações que ocorreram no âmbito geoeconômico e político global, e sobre as consequências de uma economia mundial altamente financeirizada (WAHL, 2010).

No âmbito social, a crise da desigualdade global atingiu novos extremos. Atualmente a fortuna de $1 \%$ da população mais rica do mundo é superior à riqueza dos outros 99\% (OXFAM, 2016). Além disso, poderes e privilégios estão sendo empregados para distorcer o sistema econômico, ampliando a distância entre os mais ricos e o restante da população.

Na dimensão ambiental, Stengers (2015) aponta que a mudança climática global não se apresenta mais como uma previsão alarmista. A exploração descontrolada dos recursos naturais tem destacado problemas que se acumulam, como poluição, envenenamento por agrotóxicos, esgotamento das fontes naturais, redução do volume dos lençóis freáticos, secas, inundações, etc. Para Leff (2009), os impactos dessas mudanças ambientais nas perspectivas ecológica e social ameaçam a economia como um câncer generalizado incoercível, ainda mais grave do que as crises recorrentes do capital.

Admitindo o caráter complexo e integral de tantas crises simultâneas, é possível observar que elas se dão sobre eixos mais profundos que vão além do plano econômico e adentram outras esferas. Neste contexto, em que os mecanismos vigentes não são suficientes para a criação de soluções para os problemas, constata-se a emergência de um repensar de modelos organizacionais. Considerando que, atualmente, as organizações têm um papel de grande relevância para a sociedade, elas possuem tanto o potencial de contribuir para o agravamento das crises quanto o de colaborar para a mitigação dos problemas em questão.

Para Serva e Andion (2006), a densidade organizacional é a mais elevada da História, visto que "dependemos como nunca das organizações para satisfazer a maior parte de nossas necessidades; dessa forma, elas se tornaram o palco privilegiado da cena social" (p. 20). Assim sendo, não se pode abdicar de levar em consideração o imprescindível papel das organizações e de considerar o fenômeno da "sociedade de organizações", em que elas assumem formatos variados e papéis diversos (ETZIONI, 1984). Nesse contexto, questiona-se a abordagem exclusivamente economicista das organizações, dominante em grande parte dos estudos organizacionais, uma vez que as empresas motivadas exclusivamente pelo lucro acabam contribuindo para o agravamento da concentração de poder e riqueza, para o aprofundamento das desigualdades, pobreza e degradação ambiental.

Ao considerar, portanto, a relevância do papel das organizações na sociedade contemporânea, observa-se um aumento do interesse no estudo de formatos organizacionais alternativos ao modelo hegemônico, emergindo a relevância de compreender modelos organizacionais capazes de contribuir para a mitigação dos problemas sociais e ambientais vigentes. A fim de promover respostas e soluções a esses desafios e al- 
ternativas ao reducionismo economicista, surgem novos modelos organizacionais que têm como objetivo aliar compromisso social e ambiental sem deixarem de ser viáveis economicamente.

Entre as diferentes expressões alternativas de empresas, surgem os negócios sociais como uma possibilidade à forma de organização tradicionalmente centrada na maximização do lucro. A expressão "negócio social" empregada nesta pesquisa refere-se ao modelo disseminado pelo economista e Nobel da Paz Muhammad Yunus, que entende esse tipo de empreendimento como uma organização que tem como principal propósito a criação de valor social utilizando métodos de negócios, por meio da comercialização de produtos ou serviços, nos quais "o princípio de maximização dos lucros é substituído pelo princípio do benefício social. Em vez de acumular o maior lucro financeiro possível - para ser desfrutado pelos investidores - a empresa social procura alcançar objetivos sociais" e também o lucro deve ser integralmente reinvestido na organização (YUNUS, 2010, p. 37).

Esses empreendimentos têm adquirido notoriedade graças à sua capacidade de lidar de forma inovadora com alguns dos problemas e desafios das sociedades contemporâneas, alcançando países caracterizados por níveis diferentes de desenvolvimento econômico (BORZAGA; DEPEDRI; GALERA, 2012). Levando em conta a urgência em atender às demandas sociais que emergem principalmente nos países mais pobres, o presente artigo tem como objetivo descrever a aceleradora de negócios sociais Yunus Social Business (YSB) e sua forma de atuação no contexto mundial.

\section{DESAFIOS DE ORDEM SOCIOECONÔMICA}

O cenário do final do século 20 e início do século 21 foi de crise global, ambiental, social, política e econômica, constituindo o desafio da sociedade contemporânea lidar com as multicrises. As crises que se sobrepõem e afligem o mundo são incitadas pela crença incondicional no desenvolvimento tecno-econômico, em que o crescimento, principalmente o econômico, é o motor infalível do progresso. Atualmente, numa perspectiva de globalização e neoliberalismo, o desencadeamento do capitalismo global descomedido estendeu os aspectos negativos do desenvolvimento e perpetuou a hegemonia do cálculo, do quantitativo e do lucro nas sociedades e nas vidas humanas, desconsiderando o que dificilmente pode ser calculado (MORIN, 2013).

Para além das finanças, deve-se reconhecer que as desigualdades entre as nações e entre os cidadãos do mesmo país alcançaram níveis insustentáveis, tanto nos países desenvolvidos quanto nos subdesenvolvidos. No contexto de aprofundamento da pobreza, das diferenças sociais e da escassez de recursos naturais, agravam-se as tensões que culminam em conflitos espalhados pelo mundo (GEORGE, 2010).

As desigualdades sociais entre países em desenvolvimento e desenvolvidos também devem ser consideradas. A partir da década de 90 do século 20, o Fundo Monetário Internacional (FMI) recomendou oficialmente a adoção de um conjunto de dez medidas econômicas para promover o ajustamento econômico de países subdesenvolvidos que passavam por dificuldades. Esse conjunto de medidas, elaborado por instituições como o FMI, o Banco Mundial e o Departamento do Tesouro dos Estados Unidos, denominado de Consenso de Washington, deveria representar uma "receita" à retomada do crescimento depois das crises das décadas de 70 e 80 . As dez medidas eram: abertura co- 
mercial, privatização de estatais, redução dos gastos públicos, disciplina fiscal, reforma tributária, desregulamentação, estímulo aos investimentos estrangeiros diretos, juros de mercado, câmbio de mercado, direito à propriedade intelectual (ANDERSON, 1995).

Nota-se que todas as medidas foram elaboradas para justificar a adoção de políticas neoliberais e não visam diretamente à solução ou mitigação da pobreza e das desigualdades sociais encontradas nos países em desenvolvimento. Essas medidas trouxeram consequências diversas e, em alguns casos, negativas, como a polarização entre pobres e ricos e a aceleração da exploração dos recursos ambientais, como também a crise asiática de 1997, a crise da Rússia em 1998 e a "quebra" da Argentina em 2002 (ANDERSON, 1995). Essas crises ocorreram por vários motivos, porém, com uma razão em comum, o FMI acreditou que "a liberalização dos mercados determinaria um fluxo de capital dos países mais ricos para os mais pobres, no entanto foi exatamente o contrário que aconteceu. Em vez de ocorrerem melhorias na distribuição de renda pelo mundo, a situação piorou" (1995, p. 11).

Esse processo de globalização e neoliberalismo da economia mundial acabou por contribuir para o agravamento das desigualdades sociais e econômicas entre países desenvolvidos e em desenvolvimento ou subdesenvolvidos. Assim, a partir da década de 90 veio à tona a polarização entre ricos e pobres, além da ampliação do contingente de indigentes e miseráveis ao redor do mundo. A primazia do econômico sobre o social e a confiança cega no poder de autorregulação dos mercados tornaram-se verdadeiros dogmas em torno de todo o mundo, estimulados pelo processo de globalização e de expansão sem fronteiras (LUZIO DOS SANTOS, 2014).

No âmbito social, pesquisa realizada pela ONU em 2010 revelou que mais de 1,3 milhão de pessoas no mundo viviam com menos de um dólar/dia, muitos sem ter acesso à água potável. Ademais, há mais de 800 milhões de analfabetos e 100 milhões de crianças exploradas pelo trabalho infantil. Até o século passado, a relação de desigualdade entre os $20 \%$ mais ricos e os $20 \%$ mais pobres era de 1 para cada 30 . Atualmente esta percentagem pulou de 1 para cada 80 (NUNES, 2012). Em 2016, a Oxfam levantou que o $1 \%$ mais rico da população mundial possui mais riquezas que todo o restante do planeta, e que $46 \%$ do crescimento global da renda favoreceram, principalmente, os $10 \%$ mais ricos da população mundial, ao passo que os $10 \%$ mais pobres receberam apenas $0,6 \%$. Percebe-se que a economia favorece uma parcela ínfima da população mundial e que a riqueza está ainda mais concentrada (OXFAM, 2016).

Na questão ambiental, dados do relatório elaborado pelo Programa das Nações Unidas para o Meio Ambiente (Pnuma) revelam que 60\% dos ecossistemas do planeta estão deteriorados e possuem poucas condições de se autossustentarem. Para que a atmosfera volte à estabilidade será necessário um corte de $60 \%$ nas emissões de gases estufa, atrelado a um investimento de US\$ 230 bilhões até 2030, representando 0,5\% do Produto Interno Bruto (PIB) e 1,7\% dos investimentos globais, de acordo com a Organização das Nações Unidas (NUNES, 2012).

Neste cenário marcado pela instabilidade e pela crise, o risco de colapso ecológico também deixou de ser uma previsão alarmista (LEFF, 2009, p. 15), visto que "o princípio da sustentabilidade surge no contexto da globalização como a marca de um limite e o sinal que reorienta o processo civilizatório da humanidade". Segundo o autor, a crise ambiental veio contestar a racionalidade e os modelos teóricos que impulsionaram e 
fundamentaram o desenvolvimento econômico que despreza a natureza. Segundo Foladori (2001), todos os problemas ambientais podem ser reduzidos a três: depredação de recursos, por meio da exploração do solo, da água e outras fontes, poluição por causa de detritos após o fim do processo produtivo, superpopulação e pobreza para aqueles que não conseguem entrar nesse processo. Estas três questões têm em comum os limites físicos externos com os quais a humanidade precisa lidar.

\section{ENTRE O SOCIAL E O ECONÔMICO: A Via dos Negócios Sociais}

\section{Propósito dos Negócios Sociais}

O sistema econômico vigente é marcado pela instabilidade e pela crise. O sistema capitalista de sociedade e de empresas, baseada essencialmente na maximização do lucro e exploração dos mais fragilizados, gerou vários desafios de ordem social e ambiental que anteriormente eram desprezados ou subestimados, mas que recentemente têm ganho maior dimensão nas discussões e atuação das empresas, do governo e da sociedade civil. Essas discussões abrangem questões como: o aumento das desigualdades sociais e da pobreza, a degradação ambiental e o desequilíbrio ecológico.

A fim de oferecer respostas e soluções a esses desafios e alternativas ao reducionismo economicista surgem novos modelos organizacionais, que têm como objetivo essencial a geração de valor social ou ambiental, além do valor econômico. Essas formas de empreendimentos fornecem produtos ou serviços que buscam atender demandas das populações mais pobres e vulneráveis, sua organização pode apresentar aspectos diferentes e se situar entre o modelo privado e o terceiro setor. Emergem os negócios sociais como uma das alternativas à forma de organização exclusivamente motivada pelo lucro. O conceito de negócios sociais é interpretado de diversas formas, não havendo consenso nem mesmo em relação ao emprego de sua terminologia (DEES, 2001; KERLIN, 2006; YOUNG, 2008), posto que, como em qualquer novo campo de conhecimento, há um debate sobre a definição, características e influências conceituais acerca do fenômeno.

Um conceito de negócios sociais bastante utilizado na América Latina é definido pelos pesquisadores da Social Enterprise Knowledge Network (SEKN), rede de universidades ibero-americanas dedicada à pesquisa sobre empreendedorismo social, como organizações que geram mudança social por meio de atividades de mercado. Isso inclui organizações com fins lucrativos (ONGs) ou do setor privado envolvidas em atividades empresariais típicas do setor público, que criam produtos e serviços de valor significativo (COMINI; BARKI; AGUIAR, 2012). Esta visão também reconhece como negócios sociais ou empresas sociais as organizações sem fins lucrativos que promovem algum impacto social positivo. Outras abordagens consideram apenas organizações com fins lucrativos que existem para atender a uma finalidade social e operam utilizando técnicas baseadas no mercado para atingir fins sociais.

Ainda que haja diferenças nas definições de negócios sociais, há um ponto de concordância entre elas, as diversas concepções têm a noção comum de que o empreendimento envolve o engajamento do setor privado e formas de atividade com base no mercado empresarial e na consecução dos objetivos sociais. A variedade de entendi- 
mentos deriva em parte do fato de que as empresas sociais surgem em diferentes contextos econômicos e políticos, dando origem a manifestações alternativas de um impulso subjacente comum (YOUNG, 2008).

Um negócio social difere tanto das empresas privadas tradicionais, que buscam essencialmente a maximização do lucro, quanto das organizações sem fins lucrativos. As organizações tradicionais sem fins lucrativos se mantêm basicamente por meio de doações e são impedidas de distribuir lucro líquido para os indivíduos que exercem controle sobre a organização, tais como membros, diretores ou administradores. No âmbito dos negócios sociais a situação é um pouco diferente: embora os investidores abdiquem de ganhos financeiros pessoais, eles podem receber de volta o seu investimento inicial e continuam a ser acionistas com os direitos de propriedades legais, que incluem o controle sobre a empresa. A proposta de negócio social traz um argumento para o uso eficiente dos recursos filantrópicos em contraste com a abordagem convencional de caridade (HUMBERG; BRAUN, 2014).

\section{Negócios Sociais: modelo Yunus}

A expressão "negócio social" empregado neste trabalho refere-se ao modelo disseminado pelo economista e Nobel da Paz Muhammad Yunus, que entende esse tipo de empreendimento como uma organização que tem como principal propósito resolver um problema social utilizando métodos de negócios, inclusive criação e venda de produtos ou serviços; no entanto, "o princípio de maximização dos lucros é substituído pelo princípio do benefício social. Em vez de acumular o maior lucro financeiro possível para ser desfrutado pelos investidores - a empresa social procura alcançar objetivos sociais", e o lucro deve ser integralmente reinvestido na organização (YUNUS, 2010, p. 37).

Assim, o aparecimento gradual do conceito de negócio social passou a ser entendido como uma empresa autossustentável financeiramente, que comercializa produtos ou serviços, mas sua principal finalidade é atender a alguma demanda das populações mais necessitadas e melhorar a vida dos pobres (YUNUS, 2010).

A noção de negócio social ganhou visibilidade com Yunus, que foi o primeiro a descrever a estrutura completa de negócio social como um conceito e abriu caminho para a criação de empresas nesse formato (ROSOLEN; TISCOSKI; COMINI, 2015; HUMBERG; BRAUN, 2014). As definições acerca desse tipo de empreendimento normalmente seguem a perspectiva de Yunus ao descrever negócios sociais como um subconjunto de abordagens empresariais baseadas no mercado para enfrentar os desafios sociais. Até recentemente não havia nenhum quadro conceitual para estruturar esse campo de pesquisa, também existem poucas pesquisas empíricas disponíveis que analisam esse tipo de empresa nos países em desenvolvimento (HUMBERG; BRAUN, 2014).

O primeiro negócio social concebido por Yunus teve início em 1976, em Bangladesh, onde, juntamente com alunos e professores da Universidade de Chittagong, iniciou a experiência de fornecimento de pequenos empréstimos, sem garantias e requisitos das instituições bancárias tradicionais. O projeto recebeu o nome de Grameen Bank (Banco da Aldeia) e, em 1983, tornou-se um banco oficial e passou a fornecer microcrédito às pessoas pobres de Bangladesh, principalmente mulheres da zona rural. A priorização do público feminino ocorreu devido ao contexto histórico de exploração e 
pobreza, além da percepção de que o crédito fornecido às mulheres gerava mais benefícios sociais e econômicos para toda a família, particularmente para as crianças (GROVE; BERG, 2014; YUNUS, 2008, 2010).

O banco surgiu com o objetivo de fortalecer e impulsionar pequenos empreendimentos por meio do crédito rotativo, destinado a promover a geração de emprego e renda para as famílias mais pobres de Bangladesh. A iniciativa buscou promover a independência financeira entre os pobres, que, impossibilitados de ter acesso ao crédito nos bancos por ausência de bens e fiadores, tornavam-se vítimas de agiotas que cobravam juros muito elevados, o que tornava o pagamento da dívida quase impossível (YUNUS, 2008, 2010).

O sistema de microcrédito operava por meio de concessão de empréstimos individuais, condicionados a um mecanismo coletivo de aprovação, assim, à medida que os empréstimos são pagos regularmente, a concessão é gradualmente estendida para os demais membros do grupo (GROVE; BERG, 2014). O Grameen Bank foi uma das primeiras iniciativas de negócio social e deu base para novos empreendimentos dentro dessa concepção.

O conceito de negócio social desenvolvido por Yunus recebeu atenção internacional em 2006, quando o Grupo Grameen lançou sua primeira joint venture ${ }^{4}$ de negócios sociais projetado em parceria com o Grupo Danone, uma empresa multinacional de alimentos da França. O objetivo da joint venture, chamada Grameen Danone Foods Ltda. foi combater a desnutrição entre as crianças das áreas rurais de Bangladesh, fornecendo iogurte fortificado a um preço acessível para populações de baixa renda. De acordo com os princípios de Yunus, a empresa tem de gerar lucros suficientes para ser autossustentável e expandir as operações, potencializando a atuação social, mas nem a Grameen nem a Danone podem se apropriar de qualquer lucro financeiro. Acionistas da companhia estão autorizados a recuperar o seu capital de investimento inicial, porém qualquer excedente posterior tem de ser reinvestido para a expansão da empresa e criação de novas oportunidades para ampliar o número de beneficiários (YUNUS 2010; HUMBERG; BRAUN, 2014).

Para Yunus (2010), existem dois tipos de negócios sociais. O primeiro, como já exposto, são empresas cujo foco é proporcionar um benefício social em vez da maximização dos lucros para os proprietários. Tais empresas buscam desenvolver produtos ou serviços com claro objetivo social, atendendo necessidades dos grupos menos favorecidos da população e tem como princípio a sustentabilidade e independência financeira.

O segundo tipo de negócios sociais visa ao lucro, no entanto pertence às pessoas pobres ou desprovidas de recursos, como o caso de cooperativas compostas por indivíduos de baixa renda. Neste caso, parte dos dividendos é repartida entre os trabalhadores e outra parte é destinada à ampliação do empreendimento. Desta forma, o benefício social consiste no fato de que os rendimentos e o aumento do capital social produzidos

\footnotetext{
4 "Expressão em inglês que significa "união de risco" e designa o processo mediante o qual pessoas, ou, o que é mais frequente, empresas se associam para o desenvolvimento e execução de um projeto específico no âmbito econômico e/ou financeiro" (SANDRONI, 1999, p. 315).
} 
servirão para beneficiar os pobres, ajudando-os a reduzir a pobreza ou até mesmo a sair dela completamente. Pode ocorrer ainda a combinação de ambas as formas de negócio social (YUNUS, 2010).

\section{Limites e Contradições dos Negócios Sociais}

O princípio fundamental de que as empresas sociais são criadas para resolver um problema social e ainda gerar lucro levanta várias questões-chave, isso porque a conceituação desse campo de estudo ainda está em construção. Embora haja muitas abordagens diferentes, o que todas têm em comum é a utilização de métodos de negócios para causar algum impacto social. Na definição dos negócios sociais, é importante diferenciá-los das empresas tradicionais. Embora semelhantes em muitos aspectos, esses dois tipos de organizações têm como principal diferença a sua finalidade (BARKI et al., 2015).

Existe também a necessidade de diferentes medidas de desempenho para essas empresas, além das financeiras, para avaliar o impacto social gerado pelo negócio. 0 foco na melhoria dos problemas sociais implica não só encontrar instrumentos para avaliar em que medida a questão foco está sendo resolvida, mas também um entendimento prévio da questão social-alvo, considerando que contextos culturais e políticos desempenham um papel no planejamento dos negócios e nos resultados de suas operações (GROVE; BERG, 2014).

Além disso, os negócios sociais trazem em seu conceito uma dicotomia, ainda há uma grande discussão sobre o impacto positivo que as empresas tradicionais ou até mesmo empresas sociais podem criar.

De um lado, alguns autores (PORTER; KRAMER, 2011; MACKEY; SISODIA, 2013; LONDON; HART, 2011) afirmam que as empresas tradicionais podem ter um propósito mais elevado e não buscar apenas os lucros. Nessa perspectiva, em vez de uma troca entre lucros e impacto social, poderia haver uma situação favorável para ambas as partes, em que os investimentos na área social poderiam beneficiar as empresas. Esta abordagem, no entanto, é muito criticada e combatida por outros autores, como Crane et al. (2014), por exemplo, os quais acreditam que, na maior parte do tempo, há incompatibilidade entre o impacto social e a geração de lucro financeiro. Há um questionamento sobre a possibilidade de equilíbrio entre os interesses econômicos e sociais. Apesar da ênfase na missão social, é esperado que o negócio social seja economicamente autossuficiente, no entanto um interesse pode acabar se sobrepondo ao outro.

Percebe-se que a possibilidade de congruência entre a perspectiva social e econômica desperta vários entendimentos. A ideia de reunir o impacto social das organizações filantrópicas com a lógica das empresas capitalistas tradicionais pode remeter a uma noção de empresa capitalista sustentável. A crítica a este tipo de concepção pode ser ainda mais acentuada por autores críticos como O'Connor (2002), Foladori (2001) e Schnaiberg (1997), que defendem que é irracional esperar que as empresas capitalistas tomem decisões que privilegiem o meio ambiente, nações subdesenvolvidas ou trabalhadores, pois não é da natureza do capitalismo. De acordo com esse pensamento, empresas capitalistas são definidas e conduzidas pelo lucro. Para O'Connor (2002), o inverso é mais realista, pois as empresas capitalistas tendem a tomar decisões que favoreçam nações privilegiadas e poderosas e que coloquem preocupações econômicas acima das questões ambientais e humanitárias. 
As abordagens de empresa social podem evitar refletir criticamente sobre a sua missão e o processo de criação de valor social, assim, a reflexão não está centrada na natureza e legitimidade dos atores, no seu projeto político, nem nas relações sociais em que operam.

Nessa perspectiva, a abordagem não é centrada na relação entre as esferas econômicas e políticas. Apesar de desenvolver uma visão diferente de empresa, o negócio social não desafia radicalmente o quadro institucional em que a atividade se desenvolve. É admitida certa capacidade das empresas sociais de intervir no ambiente externo, mas pressupõe-se uma partição entre as três esferas - econômica, social e política cujas fronteiras e interações são apenas parcialmente pesquisadas. Não há, assim, um enfoque macroeconômico, o que reduz todas as soluções no mercado. Questionando as categorias de negócios sociais a partir da perspectiva do lugar da economia na sociedade, o debate público e a democracia aparecem como o centro de pesquisas complementares para a empresa social (LAVILLE et al., 2016).

\section{METODOLOGIA}

A fim de promover respostas e soluções aos desafios e alternativas ao reducionismo economicista por meio da aceleradora de negócios sociais Yunus Social Business, realizamos um estudo de caso qualitativo, de caráter exploratório-descritivo.

A escolha da pesquisa qualitativa deve-se ao fato de considerar que a realidade é construída socialmente e é entendida como algo que ocorre em contextos históricos. Assim, o interesse da pesquisa está no significado construído pelas pessoas, ou seja, como elas atribuem sentido ao seu mundo e às suas experiências num momento histórico específico (MERRIAM, 2002).

Esta investigação tem caráter exploratório, considerando que é realizada em área com pouco conhecimento científico produzido e sistematizado. Também pode ser caracterizada como descritiva "quando apresenta um relato detalhado de um fenômeno social que envolva, por exemplo, sua configuração, estrutura, atividades, mudanças no tempo e relacionamento com outros fenômenos" (GODOY, 2010, p. 124). A estratégia utilizada consiste em estudo de caso (aceleradora de negócios sociais Yunus Social Business). $O$ estudo de caso sugere que o interesse maior da pesquisa consiste em interpretar os processos sociais que ocorrem em um determinado contexto, a fim de compreender uma situação em profundidade, destacando seu significado para os sujeitos envolvidos (GODOY, 2010). Buscamos no caso da aceleradora de negócios sociais Yunus Social Business ilustrar a complexidade da situação e dos aspectos nele envolvidos, e é relevante visto que apresenta informações a respeito de temas ainda pouco estudados.

Foi realizada a análise documental, a fim de buscar uma compreensão mais aprofundada sobre o processo de criação e atuação das organizações. Foram coletados dados, sobretudo no ano de 2017, de três principais fontes: artigos, livros e periódicos sobre a temática de negócios sociais, relatórios "Growing Businesses That Matter" publicados anualmente pela Yunus Social Business e informações presentes no website, reportagens e outros registros oficiais da organização. Utilizou-se a análise documental a fim de obter uma compreensão mais aprofundada sobre a atuação da organização 
estudada, o contexto histórico e social, as relações de produção de sentido, bem como fornecer material para fundamentar investigações mais aprofundadas. A análise dos documentos poderá auxiliar na leitura das particularidades da organização estudada.

\section{APRESENTAÇÃO E ANÁLISE DOS DADOS}

\section{Yunus Social Business}

De acordo com o Relatório "Growing Businesses That Matter" (YUNUS..., 2014), a Yunus Social Business - Global Initiatives (YSB) foi inspirada pelo sucesso dos negócios sociais em Bangladesh. A Organização foi fundada em 2011 por Saskia Bruysten (CEO), Sophie Eisenmann (CFO) e pelo professor Muhammad Yunus (presidente). Trata-se de uma "aceleradora social" que incuba e financia empreendimentos locais na construção de soluções aos problemas sociais, a fim de direcionar a fase inicial de empresas sociais em crescimento.

A organização tem o objetivo de replicar o modelo de negócios sociais em âmbito mundial. Além disso, a YSB busca estimular os empreendedores sociais por meio do acesso ao capital e aconselhamento empresarial da mesma forma como uma empresa start-up convencional faria a partir de uma incubadora de empresas. Ao mesmo tempo, e semelhante a um fundo de capital de risco, a YSB oferece aos credores filantrópicos a possibilidade de investir em uma carteira de negócios sociais em seus países-alvo (YUNUS..., 2014).

A proposta da YSB é de impulsionar empreendedores em economias emergentes com o intuito de resolver problemas sociais de uma forma empresarial. As empresas sociais da YSB buscam criar impacto social significativo em áreas como agricultura, saúde, energia e meio ambiente. A YSB está presente em oito regiões de economia emergente: Haiti, Colômbia, Índia, Bálcãs, Costa Rica, Brasil, Tunísia e Uganda. Nessas áreas e países, equipes locais fornecem treinamento aos empreendedores por meio de programas de aceleração adaptados à realidade local; essa ação é gratuita para os empreendedores. Posteriormente a YSB financia os empreendimentos considerados mais promissores e também fornece suporte de longo prazo para maximizar o impacto. Dessa forma, a organização trabalha com empresas sociais para ajudá-las a criar um impacto social a longo prazo de uma forma financeiramente autossustentável (YUNUS..., 2016).

No Quadro 1 são apresentadas algumas das informações consideradas relevantes nos relatórios. As empresas sociais inscritas para aceleração são empreendimentos que se candidatam para participar das ações de incubação e financiamento oferecidas pela YSB e as selecionadas são as empresas tidas como aptas para participar desse processo.

De acordo com os dados presentes nos relatórios analisados, o Haiti foi o primeiro país a receber um escritório da YSB. A organização começou a atuar no país, considerado o mais pobre das Américas, em 2011, e foi criada com o apoio da SAP, empresa de tecnologia e aplicativos de negócios. O primeiro negócio social financiado no Haiti foi um centro de treinamento para habilidades de negócios em Port-au-Prince em 2011. Atualmente, a organização administra uma carteira de 12 empresas sociais nos setores de agricultura e subsistência, educação e formação profissional e energia e meio ambiente, com a geração de 762 empregos (YUNUS..., 2016). 
Quadro 1 - Número de empresas inscritas e selecionadas

\begin{tabular}{|c|c|c|c|c|}
\hline País & \multicolumn{2}{|c|}{$\begin{array}{c}\text { Empresas sociais inscritas e } \\
\text { selecionadas para aceleração }\end{array}$} & \multirow{2}{*}{$\begin{array}{c}\text { Empregos } \\
\text { gerados } \\
762\end{array}$} & \multirow{2}{*}{$\begin{array}{l}\text { Negócios sociais por setor } \\
\text {-Agricultura e Subsistência } \\
\text {-Educação e Formação Profissional } \\
\text {-Energia e Meio Ambiente }\end{array}$} \\
\hline Haiti & $\begin{array}{c}300 \\
\text { Inscritos }\end{array}$ & $\begin{array}{c}12 \\
\text { Selecionados }\end{array}$ & & \\
\hline Colômbia & $*$ & $*$ & 636 & $\begin{array}{l}\text {-Agricultura e Subsistência } \\
\text {-Saúde e Saneamento }\end{array}$ \\
\hline Índia & $*$ & $*$ & 122 & $\begin{array}{l}\text {-Agricultura e Subsistência } \\
\text {-Energia e Meio Ambiente } \\
\text {-Saúde e Saneamento }\end{array}$ \\
\hline Albânia & $\begin{array}{c}360 \\
\text { Inscritos }\end{array}$ & $\begin{array}{c}36 \\
\text { Selecionados }\end{array}$ & 64 & $\begin{array}{l}\text {-Agricultura e Subsistência } \\
\text {-Saúde e Saneamento } \\
\text {-Outros }\end{array}$ \\
\hline Brasil & $\begin{array}{c}251 \\
\text { Inscritos }\end{array}$ & $\begin{array}{c}26 \\
\text { Selecionados } \\
\end{array}$ & $*$ & $*$ \\
\hline Uganda & $\begin{array}{c}304 \\
\text { Inscritos }\end{array}$ & $\begin{array}{c}15 \\
\text { Selecionados }\end{array}$ & 1.217 & $\begin{array}{l}\text {-Agricultura e Subsistência } \\
\text {-Energia e Meio Ambiente } \\
\text { - Saúde e Saneamento }\end{array}$ \\
\hline Tunísia & $\begin{array}{c}578 \\
\text { Inscritos }\end{array}$ & $\begin{array}{c}\mathbf{2 1} \\
\text { Selecionados }\end{array}$ & 9 & -Outros \\
\hline Costa Rica & * & $*$ & 428 & -Saúde e Saneamento \\
\hline
\end{tabular}

* Dados não disponíveis.

Fonte: Elaborado pelos autores a partir de YUNUS..., 2016 a.

A unidade da YSB na Colômbia também foi criada em 2011, originalmente como Grameen Caldas e tornou-se oficialmente YSB Colômbia em 2013. Atualmente administra duas empresas sociais, incluindo uma joint venture com a empresa de alimentação McCain. Os negócios sociais são do setor de agricultura e subsistência e saúde e saneamento. Até o momento foram gerados 636 empregos por meio dos negócios sociais incubados pela YSB Colômbia (YUNUS..., 2016b).

Ainda em 2011 a YSB instalou-se em Mumbai, na Índia. Até 2015, sete empresas sociais receberam financiamento, com dois empréstimos sendo reembolsados na totalidade, com o refinanciamento adicional de um, a fim de ampliar a escala do negócio social. As empresas sociais financiadas atuam na área de agricultura e subsistência, energia e meio ambiente e saúde e saneamento (YUNUS..., 2016b).

A YSB Albânia começou a operar em abril de 2012 com o apoio do Governo Nacional Albanês. Em 2013 participou de um programa de televisão transmitido para todo o país, a fim de identificar potenciais empreendedores sociais. Em 2014 ampliou o seu alcance ao Kosovo e no mesmo ano realizou seu primeiro programa de aceleração intensa. A YSB Albânia expandiu sua atuação nos Bálcãs em 2015 - atualmente apoia empreendedores em seis países na região. Cinco empresas albanesas receberam financiamento, com um fluxo crescente na região para 2016. Mais de 250 empresários foram apoiados nos setores de agricultura e subsistência, saúde e saneamento e outros, com a geração de 64 empregos diretos (YUNUS..., 2016b). 
No Brasil, a YSB iniciou suas operações em março de 2013 com o intuito de difundir o conceito de negócio social em todo o país. A YSB Brasil realizou quatro ciclos de aceleração desde o início e lançou uma rede universitária de negócios sociais em 2015. As atividades de financiamento no país estavam previstas para 2016 (YUNUS..., 2016b). Para esta unidade não foi possível consultar os dados referentes a empregos gerados e setores de atuação, pois os dados não estavam disponíveis nos relatórios ou no website da organização.

Em parceria com o Banco Africano de Desenvolvimento, a YSB Uganda iniciou suas atividades em novembro de 2013 e as primeiras empresas sociais foram apoiadas em 2014; atualmente já apoiou mais de cem empreendedores e financiou três empresas sociais em 2015. Os setores de atuação das empresas sociais que receberam apoio da YSB são os de agricultura, subsistência, energia e meio ambiente, com a geração de 1.217 empregos (YUNUS..., 2016b).

Em parceria com o Banco Africano de Desenvolvimento, a Tunísia foi o primeiro de uma série de países africanos a replicar o conceito de negócio social. Em 2014 lançou seu primeiro programa de aceleração, em parceria com a Universidade de Yale. Atualmente a unidade administra um portfólio de dois negócios sociais e até o momento gerou 9 empregos (YUNUS..., 2016b).

A YSB passou a operar na Costa Rica em 2014, com o apoio ao primeiro negócio social, uma joint venture com uma empresa local de alimentos, criada com o intuito de produzir alimentos para combater a desnutrição em crianças. Até o momento foram gerados 428 empregos por meio dos negócios sociais no setor de saúde e saneamento (YUNUS..., 2016b).

Para a realização desta contextualização da YSB é necessário considerar algumas limitações. Primeiramente, os critérios para seleção não estão claros nos relatórios, o que dificulta a compreensão dos parâmetros para escolha dos empreendimentos apoiados por meio de incubação e financiamento. Em segundo lugar, dados de alguns países não estão presentes no relatório, como pode ser constatado no Quadro 1, nem há justificativas para explicar a ausência dessas informações. Por outro lado, destaca-se a inconsistência das informações sobre os empregos gerados, uma vez que em nenhum momento é descrita a forma como esses valores são mensurados.

\section{Serviços aos Empreendedores}

De acordo com as informações presentes no relatório da YSB, a organização busca promover ampla divulgação nos países em que opera, principalmente por meio de workshops, conferências e eventos com parceiros locais. Assim, uma vez que são identificadas empresas sociais de alto potencial, eles também fornecem um conjunto de serviços não financeiros a fim de dimensionar seu impacto social (YUNUS..., 2016b).

Entre os serviços oferecidos estão: 1) accelerator programs; 2) 1-on-1 coaching; 3) access to markets and providers; 4) connection with a community e 5) investment readiness. O primeiro serviço oferecido são programas de aceleração de negócios sociais personalizados, com aproximadamente três meses de duração. Esta etapa inclui workshops, apresentações de líderes e especialistas e testes de mercado do produto de acordo com o modelo de negócio social (YUNUS..., 2015, 2016b). 
O serviço denominado 1-on-1 coaching é um tipo de treinamento individual oferecido por consultores especialistas e mentores locais e internacionais para fortalecer o plano estratégico, modelo de negócios e finanças para cada empreendedor dos negócios sociais previamente selecionados para participar do processo de aceleração (YUNUS..., 2015, 2016b).

Por outro lado, a fase chamada de access to markets and providers tem o intuito de facilitar parcerias com potenciais distribuidores e clientes dos negócios sociais, por meio de uma rede de contatos estabelecida pela YSB. Além disso, esta fase inclui um pacote de negociações com prestadores de serviços, como suporte contábil, jurídico e de promoção e marketing (YUNUS..., 2015, 2016b).

A atividade denominada connection with a community almeja criar uma rede de relacionamentos entre os negócios sociais, no sentido de estabelecer uma ligação entre os empreendimentos, a Yunus Social Business e o grupo Grameen. Com isso tem-se a intenção de criar oportunidades para compartilhar experiências e desafios com empreendedores que têm ideias e propósitos semelhantes para os seus negócios (YUNUS..., 2015, 2016b).

O último serviço não financeiro apresentado pela YSB (YUNUS SOCIAL BUSINESS, 2015, 2016b), investment readiness, refere-se à fase de investimento. Esta etapa consiste em um processo de preparação do empreendimento para ser direcionado ao Comitê de Financiamento da YSB. Nesta fase também são estabelecidas conexões com potenciais investidores dos negócios sociais.

A YSB destaca que, além desses serviços não financeiros prestados durante a fase de instituição do negócio social, existe também uma espécie de suporte pósinvestimento a fim de favorecer o crescimento sustentável da empresa. Embora este apoio seja geralmente fornecido com base nas necessidades dos empreendimentos, existe um acompanhamento contínuo pela YSB por meio de relatórios periódicos elaborados pelos empreendimentos, o que possibilita o acompanhamento da evolução do negócio e permite que a YSB faça algumas intervenções, que consistem em apoio com relação aos requisitos legais, contabilidade e padronização de processos, além de um papel consultivo mais específico para algumas empresas que sofrem dificuldades operacional ou financeira (YUNUS..., 2014).

\section{Financiamento}

As ações de financiamento dos negócios sociais são promovidas por meio da YSB Funds gGmbH, organização sem fins lucrativos, que reúne o capital de doadores e credores filantrópicos para financiar os negócios sociais que foram selecionados pelos escritórios locais da YSB. Os critérios de seleção incluem a capacidade empreendedora do empresário e equipe, a profundidade e amplitude de impacto social, a replicabilidade e escalabilidade do empreendimento e a força e maturidade do modelo de negócio (YUNUS..., 2015, 2016b).

Os empréstimos são geralmente estruturados como suprimentos de longo prazo com uma pequena parcela de patrimônio, levando a uma participação minoritária nas empresas, de até $25 \%$. Os empréstimos apresentam condições abaixo do mercado e períodos de carência de até dois anos, para dar um fôlego maior às empresas so- 
ciais. À medida que os negócios sociais pagam seus empréstimos, a YSB financia outros negócios sociais e/ou retorna para os credores filantrópicos na proporção da sua participação no capital total contribuído até o valor nominal do seu investimento inicial (YUNUS..., 2015, 2016b).

Figura 1 - Descrição das formas de investimento nos negócios sociais

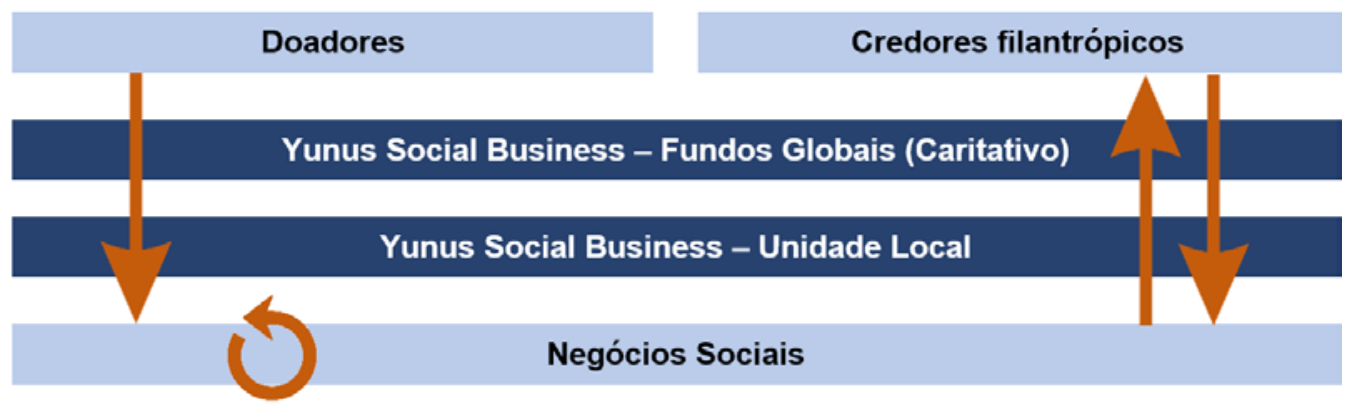

Fonte: Adaptado de YUNUS..., $2016 b$.

A Figura 1 demonstra a forma como ocorrem os financiamentos dos negócios sociais. Existem duas fontes de recursos, a dos doadores e dos credores filantrópicos. A primeira é realizada por meio de doação que pode ser dedutível de impostos. Nessa modalidade, o doador não recebe o valor doado de volta, tampouco tem participação na empresa. Na segunda fonte existe a opção do valor investido ser reembolsado ao longo do tempo. A diferença entre um investidor tradicional e um credor filantrópico é que o primeiro investe para o seu próprio ganho financeiro e o segundo busca maximizar o retorno social sobre o seu empréstimo (YUNUS..., 2014, 2015, 2016b).

Apesar de aceitar doações para financiar os negócios sociais e o trabalho de incubação, a YSB não realiza doações para as empresas sociais com as quais trabalha. As operações da YSB são conduzidas com a disciplina de um fundo de investimento, que espera que os negócios sociais operem como empresas do setor privado com base no mercado. Assim, este modelo de financiamento busca maximizar o impacto a longo prazo do capital filantrópico da seguinte maneira: financiamento por meio de empréstimos em vez de doações, pois, nesta perspectiva, entende-se que o uso dos recursos seja mais eficiente e proporciona aos negócios sociais maior possibilidade de os empreendimentos serem financeiramente autossustentáveis, para que eles continuem a gerar impacto mesmo depois que o empréstimo inicial seja reembolsado; além disso, há um requisito de que os produtos ou serviços comercializados devem atingir ao menos o seu ponto de equilíbrio para garantir a viabilidade do negócio (YUNUS..., 2015).

Percebe-se uma contradição nesse modelo de investimento da YSB nas empresas incubadas, ao se constatar que ela recebe doações, portanto não rompe com a lógica da dependência filantrópica, no entanto não realiza doações aos empreendimentos, somente empréstimos. Apesar de a organização alegar que esse procedimento é adotado para favorecer a autonomia e independência financeira dos empreendimentos, este método pode ser questionável, uma vez que a própria YSB é extremamente dependente de doações.

Para receber o investimento, o empresário e a YSB celebram um contrato que define os termos e condições do pacote de financiamento. Além disso, o empresário e sua equipe se comprometem a emitir um relatório mensal, trimestral e anual. Isso 
inclui indicadores financeiros, como o Key Performance Indicators (KPIs), de maior relevância para o negócio social específico. Esses KPIs são definidos em conjunto com os empresários durante o processo de investimento. Os relatórios também incluem informações operacionais para permitir o acompanhamento e evolução dos negócios sociais (YUNUS..., 2015, 2016b).

De acordo com último relatório da YSB (YUNUS..., 2016b), desde a sua criação, em 2011, foram investidos mais de 8,6 milhões de dólares por meio de financiamento direto ou fundos mobilizados dos parceiros e doadores para financiar 34 empresas sociais ao redor do mundo. A distribuição dos valores está representada na Figura 2, a seguir.

Figura 2 - Distribuição dos valores de financiamento da YSB

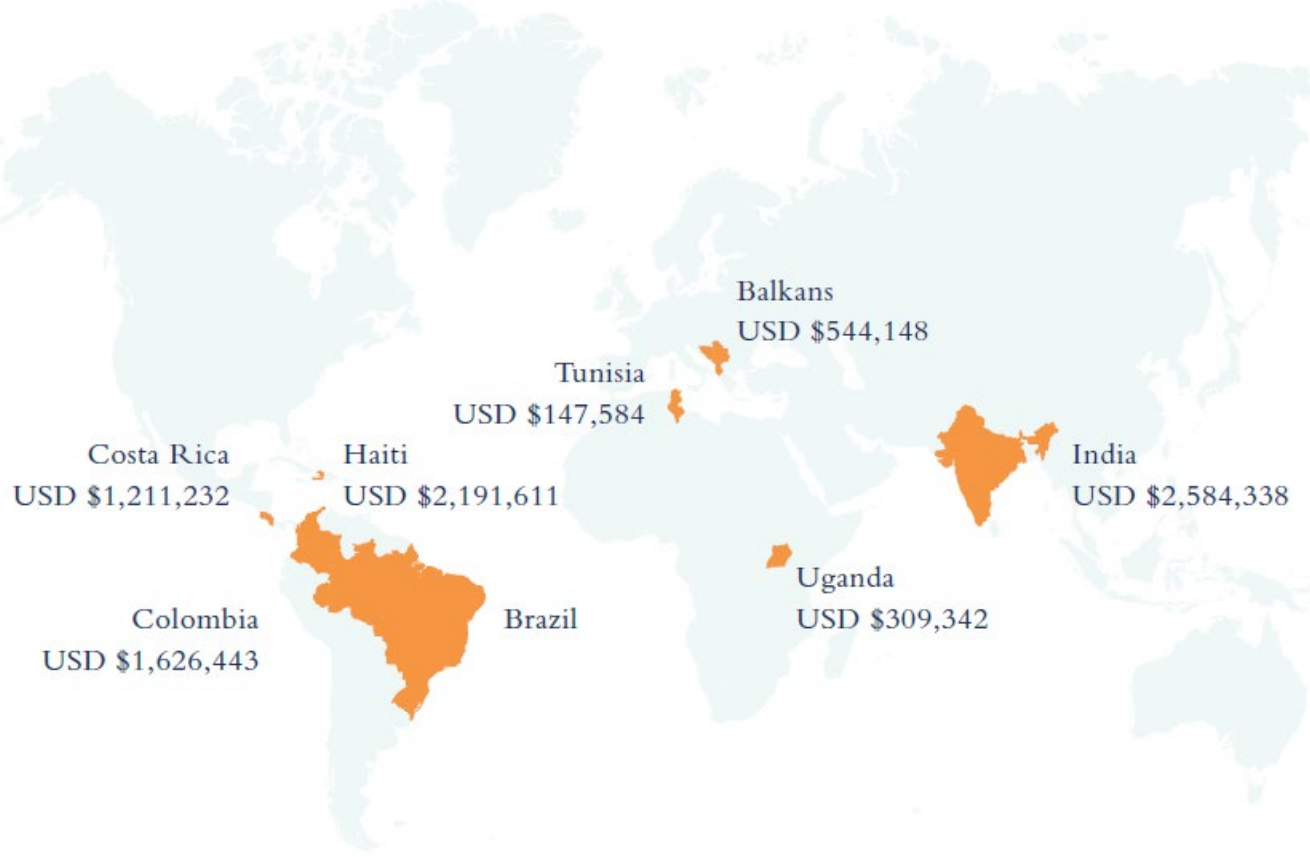

Fonte: YUNUS SOCIAL BUSINESS, 2016b.

Nota-se que os países que receberam maior volume de investimentos foram Índia e Haiti, seguidos pela Colômbia, Costa Rica, Bálcãs, Uganda e Tunísia. Até o momento no Brasil não foram realizadas ações de financiamento para os negócios sociais por meio da YSB. Ainda que a YSB expresse claramente que um dos requisitos básicos para que o negócio social seja viável é a sustentabilidade financeira, não há informações sobre os pagamentos dos empréstimos pelos empreendimentos, portanto não é possível analisar se este critério está sendo atendido pelas organizações financiadas.

\section{CONSIDERAÇÕES FINAIS}

Os negócios sociais têm pelo menos duas diferenças importantes em relação às empresas privadas tradicionais: em primeiro lugar, eles são mais complexos devido às suas formas organizacionais e institucionais e, em segundo lugar, eles são mais dependentes do seu ambiente de recursos, na medida em que estes últimos são plurais (recursos de mercado, não mercantil e não monetário). Além disso, a relação entre o im- 
pacto social e a sustentabilidade financeira é bastante complicada, uma vez que existe grande possibilidade de incompatibilidade entre os interesses sociais e econômicos da organização.

Ao analisar os dados disponíveis da Yunus Social Business no site da organização e nos relatórios publicados anualmente, é possível reconhecer algumas de suas contribuições nas regiões em que atua, principalmente ao considerar que todos esses países são subdesenvolvidos e enfrentam grandes problemas de ordem social, política e econômica. Considerando o contexto dos países, especialmente os mais pobres, e as condições para o surgimento de iniciativas que visem a contribuir para a melhoria de condições de vida dos habitantes mais vulneráveis, é preciso reconhecer a relevância do estímulo que a YSB proporciona para o surgimento e viabilização dos empreendimentos que podem de alguma forma gerar impactos positivos, ainda que localmente, uma vez que, sem o suporte da YSB, muitos desses empreendimentos poderiam não passar de boas intenções.

Apesar de reconhecer o potencial dos negócios sociais em lidar com os problemas sociais, é preciso admitir que se trata de uma lógica paliativa e é questionável se este modelo organizacional se apresenta como contributivo para enfrentar os múltiplos desafios da ordem mundial, em constante mudança, visto que as proposições dos negócios sociais não questionam o modelo econômico vigente e podem fortalecer ainda mais sua hegemonia, na medida em que utiliza a lógica do mercado para alcançar seus objetivos.

Ainda assim, entende-se que as medidas contingenciais são necessárias, uma vez que não se trata de ignorar que as soluções proporcionadas por esse modelo de negócio sejam paliativas. Apesar, no entanto, de terem um caráter reformista, os negócios sociais podem ser iniciativas realistas e viáveis nos tempos atuais, para contribuir para a mitigação dos problemas sociais, especialmente dos países mais pobres.

O negócio social como modelo e como campo de estudo acadêmico, todavia, constitui um fenômeno novo, complexo e multifacetado, ainda de difícil compreensão. Existem poucos estudos sobre a aplicação deste conceito, no entanto trata-se de um assunto emergente que atualmente conta com um número razoável de empreendimentos operando há alguns anos. Assim, o campo está aberto para pesquisas dessas novas formas de organização, que combinam objetivos antes vistos como antagônicos: geração de valor social e sustentabilidade financeira.

Entende-se como limitação desta pesquisa o acesso apenas aos dados publicados pela organização, relatórios e informações presentes em seu website. Assim sendo, os discursos presentes carregam em si um caráter institucional que pode prejudicar a pesquisa, como a omissão de informações cuja divulgação não seja do interesse da organização ou o destaque para dados que favoreçam a imagem da YSB. Buscou-se, entretanto, realizar uma leitura crítica das informações apresentadas. Para compreender com mais profundidade a atuação e relevância da YSB sugere-se a realização de estudos futuros que considerem outras fontes de dados e diferentes perspectivas dos atores sociais envolvidos no seu processo de atuação nas diferentes regiões nas quais a organização atua. 


\section{REFERÊNCIAS}

ANDERSON, P. Balanço do neoliberalismo. In: SADER, E.; GENTILI, P. (org.). Pós-neoliberalismo: as políticas sociais e o Estado democrático. Rio de Janeiro: Paz e Terra, 1995.

BARKI, E.; COMINI, G.; CUNLIFFE, A.; HART, S. L.; RAI, S. Social entrepreneurship and social business: retrospective and prospective research. RAE - Revista de Administração de Empresas, v. 55, n. 4, jul./ago., p. 380-384, 2015.

BORZAGA, C.; DEPEDRI, S.; GALERA, G. Interpreting social enterprises. Rausp - Revista de Administração da Universidade de São Paulo, v. 47, n. 3, p. 398-409, 2012.

COMINI, G.; BARKI, E.; AGUIAR, L. T. de. A three-pronged approach to social business: a Brazilian multicase analysis. RAUSP - Revista de Administração da Universidade de São Paulo, v. 47, n. 3, p. 385-397, 2012.

CRANE, A.; PALAZZO, G.; SPENCE, L. J.; MATTEN, D. Contesting the value of "creating shared value". California Management Review, v. 56, n. 2, p. 130-153, 2014.

DEES, J. G. The meaning of social entrepreneurship. Durham, USA: Center for the Advancement of Social Entrepreneurship (Case); The Fuqua School of Business; Duke University, 2001.

ETZIONI, A. Organizações modernas. São Paulo: Pioneira, 1984.

FOLADORI, G. Limites do desenvolvimento sustentável. Campinas, SP: Editora da Unicamp, São Paulo; Imprensa Oficial, 2001.

GEORGE, S. Crises convergentes: realidade, medo e esperança. In: DOWBOR, L.; SACHS, I.; LOPES, C. (Org.). Riscos e oportunidades: em tempos de mudanças. São Paulo: Editora e Livraria Instituto Paulo Freire, 2010.

GODOY, A. S. Estudo de caso qualitativo. In: GODOI, C. K.; BANDEIRA-DEMELO, R.; SILVA, A. B. (org.). Pesquisa qualitativa em estudos organizacionais: paradigmas, estratégias e métodos. 2. ed. São Paulo, 2010. GOLDERNBERG, M. A arte de pesquisar: como fazer pesquisa qualitativa em ciências sociais. 10. ed. Rio de Janeiro: Record, 2007.

GROVE, A.; BERG, G. A. Social business: defining and situating the concept. In: GROVE, A.; BERG, G. A. (ed.). Social business: theory, practice, and critical perspectives. California: Springer, 2014.

HUMBERG, K.; BRAUN, B. Social business and poverty alleviation: lessons from Grameen Danone and Grameen Veolia. In: GROVE, A.; BERG, G. A. (ed.). Social business: theory, practice, and critical perspectives. California: Springer, 2014.

KERLIN, J. Social enterprise in the United States and Europe: understanding and learning from the differences. Voluntas - International Journal of Voluntary and Nonprofit Organizations, v. 17, n. 3, p. 247-263, 2006.

LAVILLE, J. L.; HILLENKAMP, I.; EYNAUD, P.; CORAGGIO, J. L.; FERRARINI, A,; FRANÇA FILHO, G. C.; GAIGER, L. I.; KITAJIMA, K.; LEMAÎTRE, A.; SADIK, Y.; VERONESE, M.; WANDERLEY, F. Théorie de l'entreprise sociale et pluralisme: L'entreprise sociale de type solidaire. Revue Interventions Économiques, v. 54, p. 1-14, 2016. LEFF, E. Saber ambiental: sustentabilidade, racionalidade, complexidade, poder. 7. ed. Petrópolis: Vozes, 2009.

LONDON, T.; HART, S. Next generation business strategies for the base of the pyramid. New Jersey: Pearson Education, 2011.

LUZIO DOS SANTOS, L. Socioeconomia: solidariedade, economia social e as organizações em debate. São Paulo: Atlas, 2014.

MACKEY, J.; SISODIA, R. Conscious capitalism: liberating the heroic spirit of business. Boston: Harvard Business School Publishing, 2013.

MAY, T. Pesquisa social: questões, métodos e processos. 3. ed. Porto Alegre: Artmed, 2004.

MERRIAM, S. B. Qualitative research and case study applications in education. San Francisco: Allyn and Bacon, 1998.

MORIN, Edgar. A via para o futuro da humanidade. Rio de Janeiro: Bertrand Brasil, 2013.

NUNES, Leandro. Crise ambiental e social em tempos de capitalismo destrutivo. In: SEMINÁRIO DO TRABALHO, 8., 2012, Marília. Anais [...]. Marília, SP, 2012.

O'CONNOR, James. ¿Es posible el capitalismo sostenible? In: ALIMONDA, H. (org.). Ecología Política: Naturaleza, Sociedad y Utopia. Buenos Aires: Clacso, 2002.

OXFAM. Oxford Committee for Famine Relief. Uma economia para o 1\%. Oxford, UK: Oxfam, 2016.

POCHMANN, M. Desigualdade econômica no Brasil. São Paulo, SP: Ideias \& Letras, 2015.

PORTER, M.; KRAMER, M. R. Creating shared value. Harvard Business Review, v. 89, p. 62-77, 2011. 
ROSOLEN, T.; TISCOSKI, G. P.; COMINI, G. M. Empreendedorismo social e negócios sociais: um estudo bibliométrico da publicação nacional e internacional. In: SANTANA, A. L. J. de M. de; SOUZA, L. M. de (org.). Empreendedorismo com foco em negócios sociais. Curitiba: Nits; UFPR, 2015.

SANDRONI, P. Novíssimo dicionário de economia. São Paulo: Best Seller, 1999.

SCHNAIBERG, A. Sustainable development and the treadmill of production. In: BAKER, S. et al. (ed.). The politics of sustainable development: theory, policy and practice within the European Union. London \& New York: Routledge Press, 1997.

SERVA, M.; ANDION, C. Teoria das organizações e a nova sociologia econômica: um diálogo interdisciplinar. Rev. Adm. Empresas, São Paulo, v. 46, n. 2, p. 10-21, 2006.

STENGERS, I. No tempo das catástrofes: resistir à barbárie que se aproxima. São Paulo: Cosac Naify, 2015. WAHL, P. As múltiplas crises e o fracasso da governança global. In: DOWBOR, L.; SACHS, I.; LOPES, C. (org.). Riscos e oportunidades: em tempos de mudanças. São Paulo: Editora e Livraria Instituto Paulo Freire, 2010.

YOUNG, D. A unified theory of social enterprise. In: SHOCKLEY, G. E.; STOUGH, R. R.; FRANK, P. M. (ed.). Non-market entrepreneurship: interdisciplinary approaches. Cheltenham, UK: Edward Elgar Publishing, 2008.

YUNUS, M. Um mundo sem pobreza: a empresa social e o futuro do capitalismo. São Paulo: Ática, 2008.

YUNUS, M. Criando um negócio social: como iniciativas economicamente viáveis podem solucionar os grandes problemas da sociedade. Rio de Janeiro: Elsevier, 2010.

YUNUS SOCIAL BUSINESS. 2016a. Social Business. Disponível em: http://www.yunussb.com/. Acesso em: 10 jun. 2016.

YUNUS SOCIAL BUSINESS. 2014. Growing business that matter. Disponível em: http://www.yunussb.com/ wp-content/uploads/2014/09/YSB-Investment-Report-Web.pdf. Acesso em: 10 abr. 2016.

YUNUS SOCIAL BUSINESS. 2015. Growing business that matter. Disponível em: http://www.yunussb.com/ wp-content/uploads/2015/11/YSB-AnnualReport-Digital-April.pdf. Acesso em: 10 abr. 2016.

YUNUS SOCIAL BUSINESS. 2016b. Growing business that matter. Disponível em: http://www.yunussb. com/wp-content/uploads/2016/04/2015_YSB_Impact_Report.pdf. Acesso em: 10 abr. 2016. 